\title{
Acute Tryptophan Depletion Increases Translational Indices of Anxiety but not Fear: Serotonergic Modulation of the Bed Nucleus of the Stria Terminalis?
}

\author{
Oliver J Robinson*,', Cassie Overstreet', Phillip S Allen', Daniel S Pine ${ }^{2}$ and Christian Grillon' \\ 'Section on Neurobiology of Fear and Anxiety, National Institute of Mental Health, NIH, Bethesda, MD, USA; ${ }^{2}$ Section on Development and \\ Affective Neuroscience, National Institute of Mental Health, NIH, Bethesda, MD, USA
}

\begin{abstract}
Serotonin is strongly implicated in the mammalian stress response, but surprisingly little is known about its mode of action. Recent data suggest that serotonin can inhibit aversive responding in humans, but this remains underspecified. In particular, data in rodents suggest that global serotonin depletion may specifically increase long-duration bed nucleus of the stria terminalis (BNST)-mediated aversive responses (ie, anxiety), but not short-duration BNST-independent responses (ie, fear). Here, we extend these findings to humans. In a balanced, placebo-controlled crossover design, healthy volunteers $(n=20)$ received a controlled diet with and without the serotonin precursor tryptophan (acute tryptophan depletion; ATD). Aversive states were indexed by translational acoustic startle measures. Fear and anxiety were operationally defined as the increase in startle reactivity during short- and long-duration threat periods evoked by predictable shock (fear-potentiated startle) and by the context in which the shocks were administered (anxiety-potentiated startle), respectively. ATD significantly increased long-duration anxiety-potentiated startle but had no effect on short-duration fear-potentiated startle. These results suggest that serotonin depletion in humans selectively increases anxiety but not fear. Current translational frameworks support the proposition that ATD thus disinhibits dorsal raphé-originating serotonergic control of corticotropin-releasing hormone-mediated excitation of the BNST. This generates a candidate neuropharmacological mechanism by which depleted serotonin may increase response to sustained threats, alongside clear implications for our understanding of the manifestation and treatment of mood and anxiety disorders.
\end{abstract}

Neuropsychopharmacology (2012) 37, 1963-197I; doi:I0.1038/npp.2012.43; published online II April 2012

Keywords: ATD; serotonin; anxiety; startle; depression

\section{INTRODUCTION}

Serotonin is strongly implicated in mammalian stress responses, both healthy and pathological, but its precise neurobiological mode of action is surprisingly unclear. Neurocognitive and computational research suggests that serotonin inhibits aversive responses (Cools et al, 2008b; Crockett et al, 2009; Dayan and Huys, 2008, 2009; Robinson et al, 2011), but aversive responses are heterogeneous (Cassella and Davis, 1985; Davis et al, 1988; Joordens et al, 1996; Silva et al, 2004) and identifying the specific responses impacted by serotonin is critical. Particular questions exist concerning short- and long-duration aversive states, as they relate to pathological forms of fear and anxiety, respectively

*Correspondence: Dr OJ Robinson, Section on the Neurobiology of Fear and Anxiety, National Institute of Mental Health, I5K North Drive, Bethesda, MD 20892, USA, Tel: + I 30| 45I 5083, Fax: + I 301594 9959,

E-mail: oliver.j.robinson@gmail.com

Received 4 January 2012; revised 17 February 2012; accepted 8 March 2012
(Davis et al, 2010; Grillon, 2008b). Phobias, for example, are characterized by phasic responses to acute threats; such acute responses have been described with the term 'fear'. Generalized anxiety disorder, in contrast, involves more sustained responses to uncertain threats (Grillon, 2008b); such sustained responses have been described with the term 'anxiety'. In humans, the unique, differential role of serotonin in fear and anxiety remains minimally explored.

We used a well-established human startle paradigm to examine the impact of a serotonin manipulation on responses to phasic fear to an explicit threat cue (fearpotentiate startle) and anxiety to more sustained threatening contexts (anxiety-potentiated startle) (Davis et al, 2010; Grillon et al, 2011a). In both human and rodent research, explicit threat cues consist of cues that predict shocks, whereas threatening 'contexts' are conditions in which shocks are administered (Grillon et al, 2006a; Milad et al, 2007; Otto and Poon, 2006; Vansteenwegen et al, 2008). Explicit threat cues evoke phasic 'fear' responses because the associated threat is imminent and of short duration, while threatening contexts elicit more sustained 'anxious' 
responses. Sustained anxiety responses are, moreover, greatest in contexts associated with unpredictable compared with predictable shocks (Grillon et al, 2006a, 2004, 2011a).

This paradigm has two notable strengths. First, it has been well validated in humans. Anxiety-potentiated startle, but not fear-potentiated startle is increased in panic disorder and posttraumatic stress disorder (Grillon, 2008a; Grillon et al, 2009). Second, the task is translational by design and the procedures and responses have directly comparable rodent counterparts (Davis et al, 2010; Grillon, 2008 b). Such work in rodents shows that (1) the bed nucleus of the stria terminalis (BNST) supports 'anxiety-potentiated-startle', while the medial central nucleus of the amygdala drives 'fear-potentiated startle' and (2) pharmacologically, anxiety but not fear is mediated by BNST corticotropin-releasing hormone (CRH) (Davis et al, 2010). Assessing the impact of serotonergic manipulations on human 'fear-' and 'anxiety'-related startle responding thus uniquely bridges basic and clinical research on the anxietystress relationship; allowing us to dissociate the impact of serotonin on fear and anxiety while placing observed effects within the context of a well-defined neuropharmacological framework.

Previous work with this paradigm in humans showed that elevating serotonin via semichronic administration of the selective serotonin reuptake inhibitor (SSRI) citalopram (Grillon et al, 2008a) reduces anxiety-, but not fearpotentiated startle, which is consistent with work in the rodent on the effects of serotonin augmentation (Cassella and Davis, 1985; Davis et al, 1988; Inoue et al, 2011; Joordens et al, 1996; Silva et al, 2004). Of note, work in the rodent also suggests that reductions in serotonin increase sustained anxiety responses (Burghardt et al, 2004; Davis et al, 2010; Klemenhagen et al, 2005; Miles et al, 2011). However, this work has not been extended to humans. Thus, translational findings point to a plausible, well-characterized mechanism whereby reduced serotonin might promote anxiety responses (Bhagwagar et al, 2002; Harmer, 2008; Murrough et al, 2011; Soubrié, 1986), but the same effect in humans remains to be demonstrated.

To rectify this, we used acute tryptophan depletion (ATD) to globally reduce serotonin function (Booij et al, 2003; Crockett et al, 2012; Young et al, 1985) and examined its impact on fear- and anxiety-potentiated startle (Schmitz and Grillon, 2012). We predicted that, in contrast with the effects of chronic SSRIs in humans (Grillon et al, 2008a), but consistent with the effects of serotonin reductions in rodents (Burghardt et al, 2004; Cassella and Davis, 1985; Davis et al, 1988, 2010; Joordens et al, 1996; Miles et al, 2011; Silva et al, 2004), ATD would selectively increase longduration anxiety while having no effect on short-duration cue-specific fear.

\section{MATERIALS AND METHODS}

\section{Participants}

Participants were paid healthy volunteers who gave written informed consent approved by the NIMH Human Investigation Review Board and were free to withdraw from the study without penalty. Inclusion criteria included (1) no past or current psychiatric disorders as per Structured
Clinical Interview for DSM-IV (SCID; First et al, 2002), (2) no history of a psychiatric disorder in any first-degree relatives; (3) no medical condition that interfered with the objectives of the study as established by a physician, and (4) no use of illicit drugs or psychoactive medications as per history and confirmed by a negative urine screen. Participants met with a psychiatrist before providing consent. Twenty-four subjects participated in the study but two did not return for the second session and two had large numbers of trials with no startle response and were excluded from the study. The final group consisted of 20 subjects (13 males) with a mean age of 25.1 years $(S D=5.6)$.

\section{Procedure}

The procedure was similar to that of our previous psychopharmacology studies examining responses to short- and long-duration threat of shocks (Grillon et al, 2004, 2008b, 2009) and is described in detail elsewhere (Schmitz and Grillon, 2012). Subjects participated in two identical testing sessions separated by at least 1 week, with order of sessions being randomized. Before arrival, subjects were asked to follow a low-protein diet (they were given detailed instructions on how to consume $10-15 \mathrm{~g}$ of protein) during the day before arrival. They then arrived at the research center between 0830 and $1030 \mathrm{~h}$. A blood sample was taken, and subjects consumed the amino-acid tablets and the meal prepared by the metabolic kitchen. They were then allowed to consume water and were given a low-protein lunch. After a resting period of $\sim 3.5 \mathrm{~h}$ to ensure low tryptophan levels (Carpenter et al, 1998), subjects moved to the psychophysiology laboratory where the equipment was set up (an $\sim 45$ min process) and they completed the startle paradigm. After this, a second blood sample was taken. It is conceivable that further depletion occurred during the testing period and that the depletion at this blood sample time point is somewhat greater than that observed mid experiment, but technical constraints meant that it was not possible to take a blood sample during the startle procedure.

\section{Acute Tryptophan Depletion}

A double-blind crossover design was implemented with each subject being exposed to each treatment - placebo and ATD - on separate sessions. The order of treatment was counterbalanced across subjects. On both visits subjects consumed 70 tablets and a meal (apple juice, apple sauce, vanilla pudding, decaf coffee, sugar, non-dairy creamer). On the depletion day, the tablets contained balanced amino acids minus tryptophan $(4.2 \mathrm{~g}$ L-isoleucine, $6.6 \mathrm{~g}$ L-leucine, $4.8 \mathrm{~g}$ L-lysine, $1.5 \mathrm{~g}$ L-methionine, $6.6 \mathrm{~g} \mathrm{~L}$-phenylalanine, $3.0 \mathrm{~g}$ L-threonine, $4.8 \mathrm{~g} \mathrm{~L}$-valine), whereas on the placebo day the tablets contained $31.5 \mathrm{~g}$ lactose, and the food was mixed with Nestle Nutrition Beneprotein Whey Powder (Nestle, Vevey, Switzerland), which included $2.25 \mathrm{~g}$ tryptophan (see Supplementary information). On both sessions, subjects consumed lunch before completion of the startle paradigm (mashed potato with butter and non-dairy creamer, green beans with butter, salad (green leaf lettuce, celery, olive oil, and balsamic vinegar), apple sauce, vanilla pudding, cherry Italian ice, diet lemonade, salt, pepper), with Nestle Nutrition Beneprotein Whey Powder added on the placebo 
day only. The two meals were given to avoid the effects of hunger, which are frequently observed during tryptophandepletion studies and commercial nutritional supplement was provided on the placebo day (in contrast to some recent procedures; eg, Cools et al, 2008b; Robinson et al, 2011; and Robinson and Sahakian, 2009) because it successfully avoided the tryptophan and tryptophan ratio increase which is frequently observed on the placebo day.

\section{Startle Paradigm}

The electrodes to record the eyeblink/startle reflex were first attached and a startle habituation procedure consisting of nine startle stimuli (every 18-25 s) was conducted to reduce initial startle reactivity. The shock electrodes were then attached on the forearm and a shock workup procedure was initiated to set the shock intensity at a highly annoying level. Immediately after this, the threat experiment was started. It comprising three types of $150 \mathrm{~s}$ conditions, a noshock condition $(\mathrm{N})$, a predictable-shock condition $(\mathrm{P})$, and an unpredictable-shock condition (U). In each condition, an 8-s cue was presented four times. The cues consisted of different geometric colored shapes for the different conditions. The cues were signals for a shock only in the $\mathrm{P}$ condition but had no signal value in the $\mathrm{N}$ and $\mathrm{U}$ conditions (see Figure 1 for a schematic).

Participants received precise verbal and written instructions regarding risk of shock in each condition, including the contingency between shocks and cues in $\mathrm{P}$ and $\mathrm{U}$. Specifically, they were told that in the $\mathrm{P}$ condition shocks could be administered only in the presence of the threat cue and that in the $U$ condition shocks could be administered at any time. Subjects were also informed that they could receive up to 12 shocks. This verbal instruction avoided
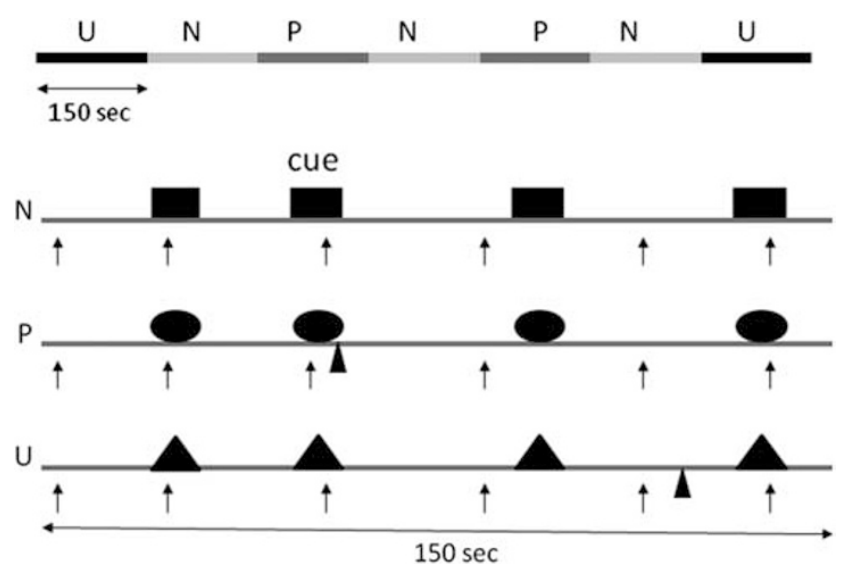

Figure I Schematic of the experiment. There were three conditions: no shock $(N)$, predictable shock $(P)$, and unpredictable shock $(U)$. Each subject was presented with two series, each including three $N$, two $P$, and two $U$ in each of the two orders (UNPNPNU as shown or PNUNUNP). Each N, P, and $U$ condition contained four 8 -s cues of different colors and geometric shapes (for illustration purposes, the cues are squares in $N$, circles in $P$, and triangles in $U$ ). In each $P$ condition, a shock (indicated by $\boldsymbol{\Delta}$ ) was randomly associated with one of the four threat cues; it was administered $7.5 \mathrm{~s}$ after its onset. In each $\cup$ condition, a shock was administered randomly in the absence of the cues. In the $\mathrm{N}$ condition, no shock was administered. Startle stimuli (indicated by $\uparrow$ ) were delivered in the presence and in the absence of the cue (ie, during intertrial intervals) (Grillon et al, 20 I Ib) (reprinted by permission of Biological Psychiatry, 2011). potential interpretation confounds which would be associated with a non-instructed conditioning design. Instructions were also showed on a computer monitor throughout the experiment displaying the following information: 'noshock' $(\mathrm{N})$, 'shock only during shape' $(\mathrm{P})$, or 'shock at any time' (U). In each $\mathrm{N}, \mathrm{P}$, and $\mathrm{U}$ condition, six acoustic startle stimuli were delivered: (1) three during intertrial intervals (ITIs; ie, in the absence of cues), one at times 15-52 s, a second at time $53-96 \mathrm{~s}$, and a third at time $97-140 \mathrm{~s}$ following the beginning of a condition and (2) one during three of the four cues, 5-7 s following cue onset.

The threat experiment consisted of two series with a 5-10 min rest between series. Each series started with the delivery of four startle stimuli (pre-threat startle) and consisted of three $\mathrm{N}$, two $\mathrm{P}$, and two $\mathrm{U}$ in one of the following two orders: PNUNUNP or UNPNPNU. Each participant received both orders, with half the participants starting with $P$ and the other half starting with $U$. One shock was administered in each individual $\mathrm{P}$ and $\mathrm{U}$ condition for a total of eight shocks. In each $\mathrm{P}$, the shock was randomly associated with one of the four threat cue, being administered $7.5 \mathrm{~s}$ following the onset of that cue. The shock was given either 7 or $10 \mathrm{~s}$ following the termination of a cue in the unpredictable condition. No startle stimuli followed a shock by $<10 \mathrm{~s}$.

The Spielberger's state portion of the state-trait anxiety inventory questionnaire (Spielberger, 1996) was administered three times: (1) arrival (pre-treatment), (2) $\sim 3 \mathrm{~h}$ after ingestion of placebo/ATD, and (3) $\sim 1 \mathrm{~h}$ later, upon arrival in the psychophysiology laboratory. In addition, after each series, subjects retrospectively rated their anxiety level in the presence of the cues and in their absence (ITI) in each condition $(\mathrm{N}, \mathrm{P}, \mathrm{U})$ on an analog scale ranging from 0 (notat-all anxious) to 10 (extremely anxious). Immediately after the last recording, subjects were also asked to retrospectively rate the level of shock pain experienced during testing on an analog scale ranging from 0 (not-at-all painful) to 10 (extremely painful).

\section{Stimuli and Physiological Responses}

Stimulation and recording were controlled by a commercial system (Contact Precision Instruments, London, England). The acoustic startle stimulus was a $40-\mathrm{ms}$ duration, 103-dB (A) burst of white noise presented through headphones. The eyeblink reflex was recorded with two electrodes placed under the left eye. The electromyographic (EMG) signal was amplified with bandwidth set to $30-500 \mathrm{~Hz}$ and digitized at a rate of $1000 \mathrm{~Hz}$. The shock was administered on the left wrist.

\section{Level of Amino Acids}

Two blood samples were taken; one just as the subject arrived (T0) and a second immediately following the psychophysiological testing ( $\mathrm{T} 1 ; \sim 5 \mathrm{~h}$ later). Plasma was spun out from the sample and frozen before analysis for free tryptophan and large neutral amino-acid ( $L$ LNAA) composition. Depletion was confirmed by comparing the change in the ratio between these two measures from the first to the second time point. Due to difficulties with blood drawing, these measures were unavailable for the placebo visit of one subject. 


\section{Data Analysis}

The EMG eyeblink was rectified and smoothed using a 10point moving average. Peak magnitude of the startle/blink reflex was determined in the $20-100 \mathrm{~ms}$ time frame following the stimulus onset relative to a 50 -ms prestimulus baseline. The magnitude scores were (1) standardized into T-scores based on data across sessions within each participant, (2) averaged within each condition, and (3) analyzed with analyses of variance (ANOVAs) with repeated measures. Consistent with our previous studies, fear-potentiated startle and anxiety-potentiated startle were analyzed separately (Grillon et al, 2004, 2008b, 2009). Fearpotentiated startle was defined as the increase in startle magnitudes from ITI to the threat cue in the P condition. Anxiety-potentiated startle was defined as the increase in ITI startle reactivity from $P$ to $U$ and from $N$ to $U$. Fearpotentiated startle during $\mathrm{P}$ was analyzed in a Stimulus Treatment (Placebo, ATD) $\times$ Stimulus Type (ITI, cue) ANOVA. Anxiety-potentiated startle was analyzed in a Treatment (Placebo, ATD) $\times$ Condition $\left(\mathrm{N}_{\text {ITI }}, \mathrm{P}_{\text {ITI }}, \mathrm{U}_{\text {ITI }}\right)$ ANOVA. Prior work has demonstrated that the $\mathrm{U}_{\text {ITI }}$ condition is considerably more anxiogenic than the $\mathrm{P}_{\text {ITI }}$ condition (Grillon et al, 2006a; Mineka and Hendersen, 1985). The variable 'order of treatment' was initially added to the models but because this variable did not significantly affect the results (no interaction effect with treatment) it was dropped from the analyses. Alpha was set at 0.05 for all statistical tests.

\section{RESULTS}

\section{Depletion Check}

A significant two-way ATD by time interaction was seen in the TRP/ $\Sigma$ LNAA ratio $(\mathrm{F}(1,18)=51.1, p<0.0001)$ driven by an $81.9 \%$ decrease in the TRP/ 2 LNAA ratio between T0 $(0.16)$ and T1 $(0.03)$ on the ATD visit $(\mathrm{F}(1,18)=254$, $p<0.0001)$ but no significant change in the TRP/ $\Sigma$ NAA ratio between T0 (0.15) and T1 (0.19) on the BAL visit $(\mathrm{F}(1,18)=2.4, p=0.14)$. In addition, the $\mathrm{T} 0$ ratios were the same on both visits $(\mathrm{F}(1,18)=0.34, p=0.57)$, but $\mathrm{T} 1$ ratios were significantly decreased on the depletion $v s$ placebo visit $(\mathrm{F}(1,18)=63, p<0.0001)$. All psychophysiological differences can thus be attributed to a tryptophan decrease on the depletion day.

\section{Startle Magnitude}

Table 1 shows the mean startle magnitude during the habituation, pre-threat, and during ITI and the cues in each condition.

Baseline startle. To examine the effect of treatment on baseline startle, the mean habituation and mean pre-threat startle magnitudes were compared between treatments in a Treatment (Placebo, ATD) $\times$ Phase (habituation, Prethreat) ANOVA with repeated measures. There was a trend for baseline startle (Table 1) to be increased by ATD, but this effect failed to reach significance $(F(1,19)=3.6$, $p=0.07)$.

Cued fear-potentiated startle. Fear-potentiated startle was defined as the increase in startle from ITI to the threat cue in the $\mathrm{P}$ condition (Table 1). Fear-potentiated startle was not affected by ATD. As expected (Grillon et al, 2006b), there was a Stimulus Type main effect $(\mathrm{F}(1,19)=43.5, p<0.0009)$, reflecting larger startle during the threat cue relative to ITI in P. This effect was not affected by ATD (Treatment $x$ Stimulus Type interaction, $\mathrm{F}(1,19)=0.09, p=0.76)$.

Anxiety-potentiated startle. Anxiety-potentiated startle was defined as the increase in ITI startle magnitude from $\mathrm{N}_{\text {ITI }}$ to $\mathrm{P}_{\text {ITI }}$ and from $\mathrm{N}_{\text {ITI }}$ to $\mathrm{U}_{\text {ITI }}$. Anxiety-potentiated startle was increased by ATD (Table 1; Figure 2). As expected (Grillon et al, 2006b), there was a Condition main effect $(\mathrm{F}(2,38)=31.5, p<0.0009)$, reflecting larger startle magnitude during $\mathrm{P}_{\text {ITI }}(\mathrm{F}(1,19)=36.0, p<0.0009)$ and $\mathrm{U}_{\text {ITI }}$ $(\mathrm{F}(1,19)=51.5, p<0.0009)$ compared with $\mathrm{N}_{\text {ITI }}$ as well as larger $\mathrm{U}_{\text {ITI }}$ startle magnitude compared with $\mathrm{P}_{\text {ITI }}$ $(\mathrm{F}(1,19)=9.0, p<0.007)$. Importantly, there was a significant Treatment $\times$ Condition interaction $(\mathrm{F}(2,38)=4.5, p<0.02)$ that confirmed that anxiety-potentiated startle was impacted by ATD. Follow-up analyses showed that ATD increased anxiety-potentiated startle in both the $\mathrm{P}(\mathrm{F}(1,19)=5.1$, $p<0.03)$ and the $\mathrm{U}(\mathrm{F}(1,19)=7.0, p<0.02)$ conditions.

\section{Subjective Anxiety, State Anxiety, and Pain}

The retrospective ratings of anxiety are shown in Table 1 and the state anxiety and pain ratings are shown in Table 2. The state anxiety scores were analyzed with a Treatment

Table I Mean (SEM) Startle Magnitude (T Scores) During Startle Habituation and Pre-Threat

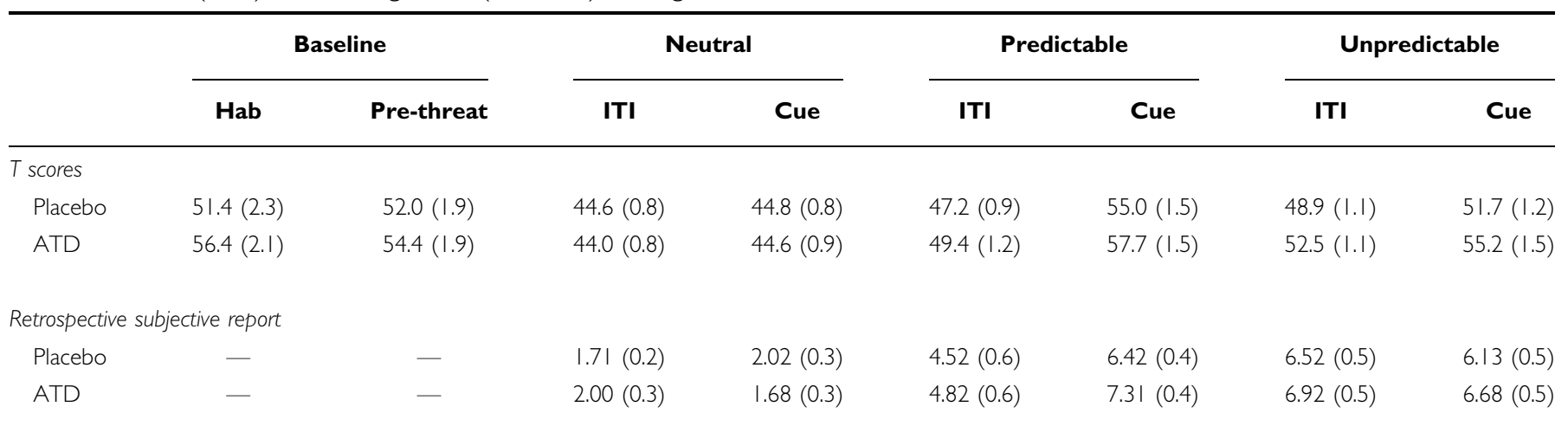

Mean (SEM) startle magnitude and retrospective subjective reports of fear and anxiety during the cue and ITI in each condition. 


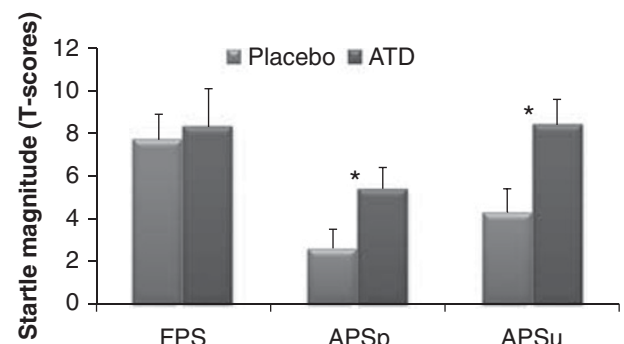

Figure 2 Fear-potentiated startle (FPS) and anxiety-potentiated startle scores on each of two within-subject treatment visits (placebo and ATD). FPS is the difference score between startle magnitude during the threat cue and during ITI in the predictable condition. Anxiety-potentiated startle scores were calculated for the predictable and unpredictable condition as the difference score between ITI startle magnitude in the predictable condition and the neutral condition (APSp) and the unpredictable condition and the no-shock condition (APSu), respectively. Anxietypotentiated startle, but not fear-potentiated startle, was significantly increased by ATD compared with placebo. *Indicates a significant $(p<0.05)$ effect. Error bars represent SEM.

(placebo, ATD) $\times$ Phase (baseline, post-treatment, laboratory) ANOVA. None of the main effects or interactions were significant (all $p>0.1$ ). The retrospective anxiety ratings were analyzed using similar ANOVAs as the startle data, first by examining fear in the $\mathrm{P}$ condition and then anxiety across $\mathrm{N}, \mathrm{P}$, and $\mathrm{U}$. In the $\mathrm{P}$ condition, the Treatment (placebo, ATD) $\times$ Stimulus Type (ITI, CS) ANOVA revealed only a significant Stimulus Type main effect $(\mathrm{F}(1,18)=32.7$, $p<0.0009)$ with no significant differential effect of Treatment on fear. Retrospective anxiety during ITI in the N, $\mathrm{P}$, and $\mathrm{U}$ conditions was analyzed using a Treatment (placebo, ATD) $\times$ Condition $\left(\mathrm{N}_{\text {ITI }}, \mathrm{P}_{\text {ITI }}, \mathrm{U}_{\text {ITI }}\right)$ ANOVA. The Condition main effect was significant $(\mathrm{F}(2,36)=62.6$, $p<0.0009$ ), due to greater subjective anxiety during $\mathrm{P}_{\text {ITI }}$ vs $\mathrm{N}_{\text {ITI }}(\mathrm{F}(1,18)=32.6, p<0.0009)$, $\mathrm{U}_{\text {ITI }}$ vs $\mathrm{N}_{\text {ITI }}(\mathrm{F}(1,18)$ $=151.7, p<0.0009)$, and $\mathrm{U}_{\text {ITI }}$ vs $\mathrm{P}_{\text {ITI }}(\mathrm{F}(1,18)=24.2$, $p<0.0009)$. None of these effects were affected by ATD (all $p>0.1$ ).

\section{DISCUSSION}

Consistent with hypotheses, we found that reducing serotonin via ATD increased eyeblink startle-reflex potentiation to long-duration contextual threat but not shortduration explicit threat cues. This has key implications for our understanding of serotonin, which is strongly involved in the expression and treatment of mood and anxiety disorders, but which still has a largely unknown method of action. The present startle paradigm is a well-established translational paradigm recruiting defined neural and pharmacological substrates (which are largely beyond the temporal and spatial resolution of current functional imaging techniques in humans) and thus provides a clear framework in which to understand the impact of serotonin reduction on anxiety responding.

Our primary finding is that ATD significantly increased the sustained potentiation of startle (anxiety-potentiated startle) in the $\mathrm{P}$ and $\mathrm{U}$ conditions $\left(\mathrm{P}_{\text {ITI }}\right.$ and $\left.\mathrm{U}_{\text {ITI }}\right)$. This concurs with, and provides translational validity to, rodent findings (Burghardt et al, 2004; Davis et al, 2010;
Table 2 Mean Spielberger (1996) State Anxiety Ratings at each Time Point, and Shock Ratings (SEM)

\begin{tabular}{llccc}
\hline & \multicolumn{3}{c}{ State anxiety } & $\begin{array}{c}\text { Subjective } \\
\text { pain }\end{array}$ \\
\cline { 2 - 4 } & Baseline & $\begin{array}{c}\text { Post- } \\
\text { treatment }\end{array}$ & $\begin{array}{c}\text { Psycho- } \\
\text { physiology } \\
\text { laboratory }\end{array}$ \\
\hline Placebo & $26.7(1.4)$ & $27.6(1.5)$ & $27.6(1.4)$ & $5.8(0.5)$ \\
ATD & $28.0(1.2)$ & $28.2(1.3)$ & $30.0(1.4)$ & $6.2(0.5)$ \\
\hline
\end{tabular}

Klemenhagen et al, 2005; Miles et al, 2011), which, in turn, provide clues as to the neuropharmacological underpinnings of this effect. In particular, the anxiety-potentiated startle response is driven by a well-defined circuit between the BNST and the amygdala (Davis et al, 2010; Grillon, 2008b). As such, the findings indicate that a global reduction in serotonin brought about by ATD (Crockett et al, 2012) increases activity within this circuit. The precise mechanism by which this occurs is unclear, but one possibility is that it is driven by an interaction between serotonin and CRH, a stress hormone that has a welldefined role in modulating the BNST-linked startle circuit (Davis et al, 2010). In particular, during anxiety responses, the lateral central nucleus of the amygdala is thought to activate the BNST via excitation of amygdala-BNST CRH neurons, which then drive increased BNST-mediated startle responses (Davis et al, 2010). However, these BNSTterminating $\mathrm{CRH}$ neurons receive innervation from dorsal raphe-originating serotonergic neurons (Phelix et al, 1992), which modulate this CRH response. In particular, serotonin reduction via ATD increases CRH (Tyrka et al, 2004) but increasing serotonin via chronic SSRI administration reduces CRH (de Bellis et al, 1993). Administration of hydrocortisone, which increases BNST CRH levels (Schulkin et al, 2005) also has an identical effect to the ATD effect seen here (Grillon et al, 2011b). As such, one possibility is that serotonin inhibits CRH release in BNST, which then prevents BNST-mediated startle potentiation during anxious responding (Figure 3). Consistent with this, in-vitro whole-cell patch-clamp electrophysiological findings have shown that serotonin in the BNST can, via 5-HT1A receptors, inhibit BNST activation (Levita et al, 2004), especially in the presence of CRH (Hammack et al, 2009). Indeed, CRH is thought to flip serotonin's role from a 5HT2A, 5-HT2C, and 5-HT7-mediated excitatory role in the BNST to a 5-HT1A-mediated inhibitory role (Hammack et al, 2009). As such it is neither serotonin, nor CRH alone which mediates this effect, but the interaction between them. The reduction in anxiety-potentiated startle following an increase in serotonin (via chronic SSRI administration) (Grillon et al, 2008a) may therefore be driven by increased serotonin function inhibiting CRH release in the BNST, thereby reducing startle magnitude to sustained aversive contexts (Grillon et al, 2008a). The present effect of ATD, by contrast, may be the flipside of the same coin: reduced serotonin disinhibiting CRH-mediated anxiety responses. This neuropharmacological inhibitory mechanism concurs remarkably with recent neurocognitive and computational data which suggest that the role of serotonin is in the inhibition of responses toward aversive stimuli 


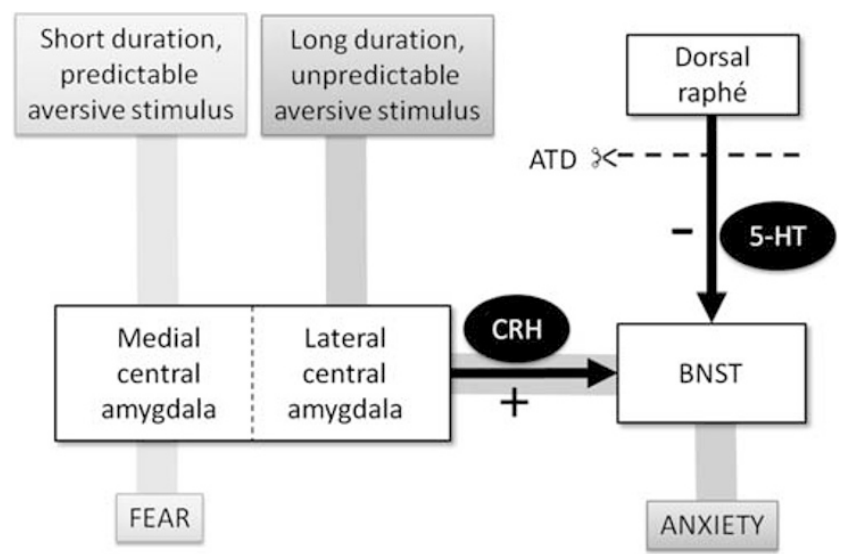

Figure 3 Proposed model of serotonergic action on anxiety. Corticotropin-releasing hormone (CRH)-induced excitation of the bed nucleus of the stria terminalis BNST (and subsequent anxiety responding) is inhibited by serotonergic $(5-\mathrm{HT})$ neurons from the dorsal raphé nucleus (Hammack et al, 2009). Acute tryptophan depletion (ATD) removes this inhibition and allows for increased $\mathrm{CRH}$-induced, BNST-driven anxiety responding, while having no effect on fear responding. Disruption of this serotonergic inhibitory mechanism may be what leads to the increased aversive responding in anxiety disorders and depression (Cools et al, 2008a; Dayan and Huys, 2009; Grillon, 2008b). '+', excitatory connection and '-', inhibitory connection.

(Cools et al, 2008b; Crockett et al, 2009; Dayan and Huys, 2009; Robinson et al, 2011). However, these psychological findings did not stratify punishment by the nature of the threat (ie, short $v s$ long duration) or adopt such directly translational paradigms. The present findings thus extend these psychological findings to encompass a specific subset of sustained duration aversive responding and, via translation, a specific neural circuit which may be disinhibited by serotonin reduction (Robinson et al, 2011). In addition, these findings may be related to the dorsal raphe-dependent serotonergic 'inhibitory avoidance' mechanism proposed by Graeff and colleagues (Zangrossi Jr et al, 2001).

By contrast, serotonin reduction has no effect upon fear responding as measured by short-duration startle potentiation to the explicit threat cue. This lack of significant impact on fear-potentiated startle demonstrates that the effect of serotonin reduction is not a generic increase in startle potentiation. Rather, the disinhibitory effect of ATD on anxiety-potentiated startle is restricted to the BNST and $\mathrm{CRH}$-mediated sustained anxiety circuit. Thus, serotonin may have no effect on the medial central nucleus of the amygdala-mediated fear-potentiated startle response (Davis et al, 2010; Figure 3). Critically, although there are CRH receptors in the amygdala, this circuit has also been shown to not depend upon CRH (de Jongh et al, 2003; Toufexis et al, 2004). This therefore provides additional support for the proposition that serotonin exerts its influence over anxiety responding by mediating $\mathrm{CRH}$ in the BNST. Of course, more work is necessary to fully clarify this mechanism, but the well-established nature of the present psychophysiological paradigm provides us with a head start with regards to the underlying neuropsychopharmacology (Davis et al, 2010; Grillon, 2008b). Indeed, the size of structures like the BNST and amygdala subunits, alongside the temporal differences between fear and anxiety responses, puts them largely beyond the current resolution of functional magnetic resonance imaging. As such, the only way to assess these questions at present may be via the use of such translational paradigms.

Taken together, these findings have implications for our understanding of psychiatric disorders. In particular, the present dissociation may explain why serotonergic medications are more likely to benefit individuals demonstrating symptoms of anxiety rather than fear (ie, generalized anxiety disorders rather than phobia, for which the firstline treatments are SSRIs and cognitive behavioral therapy, respectively; McNaughton and Corr, 2004). Moreover, these findings have implications for our understanding of resilience to mood and anxiety disorders. Specifically, serotonin is thought to promote resilience to such disorders through its role in the inhibition of aversive responses (Robinson, 2011; Robinson et al, 2011). The present data suggest that one way in which this protective role is exerted is via the inhibition of $\mathrm{CRH}$-mediated BNST responses to uncertain aversive stimuli. In healthy individuals, this serotonergic inhibition of anxious responses may be achieved via top-down control of raphe nuclei by the prefrontal cortex (Amat et al, 2005; Passamonti et al, 2012), which results in serotonergic inhibition of $\mathrm{CRH}$ anxiogenic action in the BNST. From a psychological perspective, this putative serotonergic circuit could plausibly afford a means to avoid worrying about sustained threats that one cannot predict or control (indeed the Amat et al (2005) reference argues that this top-down inhibition may depend upon controllability of the aversive stimulus, which is strongly intertwined with predictability; Mineka and Hendersen, 1985). As such, one hypothesis might be that when serotonin is depleted in depression (Bhagwagar et al, 2002; Harmer, 2008) or in anxiety (Murrough et al, 2011; Soubrié, 1986), the lack of such protection leads to longduration ruminatory aversive thoughts (Cooney et al, 2010; Nolen-Hoeksema, 2000) and responses (Grillon, 2008b). Thus, this serotonergic prefrontal-raphe-BNST circuit may prove a more precise target for the treatment of mood and anxiety disorders (Insel et al, 2010; Sanislow et al, 2010), but this will of course require further study.

As a potential caveat, it is important to note that previous work with this task showed that acute SSRI administration increased some anxiety responses (Grillon et al, 2006c) but also increased fear responding. This is distinct from the effects of chronic SSRI administration (Grillon et al, 2008a) that reduced anxiety responses. This discrepancy is partially consistent with the proposition that SSRIs have, somewhat paradoxically, opposite effects when administered acutely and chronically (Bhagwagar et al, 2002). It has been argued that this may be because acute SSRIs actually serve to reduce serotonin levels via autoreceptor feedback effects (Chamberlain et al, 2006). However, this effect is far from clear and acute SSRIs can, in fact, immediately induce some of the same neurocognitive effects as chronic SSRIs (for a review, see Harmer, 2008). As such, the anxiogenic effects of acute SSRIs may not necessarily be serotonergically mediated. This would explain why, unlike ATD, acute SSRI administration also increased fear responding, and why a closer reciprocity was seen between ATD and chronic SSRI treatment (which both have relatively more defined effects 
on serotonin). Further research is, however, necessary to understand the neurochemical effects of acute SRRIs, especially on distinct 5-HT receptor subtypes (Zangrossi Jr et al, 2001), before we can draw too many conclusions. On a related note, the impact of ATD upon serotonin has recently been drawn into question (van Donkelaar et al, 2011; but see Crockett et al, 2012) so this close reciprocity between the effects of ATD in the present study and chronic SSRIs in our previous study provides additional support for the serotonergic basis of ATD.

As a final caveat, it should be noted that our depletion technique was somewhat novel, and although it achieved its primary aim of depleting tryptophan ratio on the depletion day (while having no significant effect upon the placebo day), the possibility that subjects were able to subjectively distinguish the sessions, or that the depletion was not at its maximal point during testing cannot be fully ruled out. This seems unlikely, given the correspondence between the amino-acid analysis and the reflexive (ie, non-subjective) startle measure, the lack of an effect of treatment on subjective measures, and the clear correspondence between the present effects and those of chronic SSRIs, but it is worth considering.

\section{Conclusions}

The present study extends prior rodent work by providing the first evidence that a global reduction in the serotonin precursor tryptophan can increase psychophysiological concomitants of anxiety but not fear in humans. This clarifies that the role of serotonin is not only in the inhibition of aversive responses, but also in the inhibition of responses to sustained aversive stimuli. As such, we argue that the reduced serotonin in disorders like depression and anxiety may exert their pathological effects via the disinhibition of serotonergic dorsal raphé control of CRH-mediated BNST-driven anxiety responses (Figure 3). This further finesses our understanding of the role of serotonin in emotional processing and provides a more precise target for treatment and detection of mood and anxiety disorders. The mechanism by which one of the most ubiquitous neurotransmitters contributes to the treatment and manifestation of mood and anxiety disorders is still largely mysterious and given the enormous emotional, social, and financial cost of these disorders such clarification is of clear value.

\section{ACKNOWLEDGEMENTS}

This research was supported by the Intramural Research Program of the National Institutes of Mental Health. We are grateful to Michael Jackson, Angie Wu, Joan Mallinger, and Allison Letkiewicz for enormous amounts of help and support.

\section{DISCLOSURE}

The authors declare that, except for income received from the primary employer, no financial support or compensation has been received from any individual or corporate entity over the past 3 years for research or professional service and there are no personal financial holdings that could be perceived as constituting a potential conflict of interest. Dr Pine has received compensation for activities related to teaching, editing, and clinical care that pose no conflicts of interest.

\section{REFERENCES}

Amat J, Baratta MV, Paul E, Bland ST, Watkins LR, Maier SF (2005). Medial prefrontal cortex determines how stressor controllability affects behavior and dorsal raphe nucleus. Nat Neurosci 8: $365-371$.

Bhagwagar Z, Whale R, Cowen PJ (2002). State and trait abnormalities in serotonin function in major depression. $\mathrm{Br} \mathrm{J}$ Psychiatry 180: 24-28.

Booij L, Van der Does AJW, Riedel WJ (2003). Monoamine depletion in psychiatric and healthy populations: review. Mol Psychiatry 8: 951-973.

Burghardt NS, Sullivan GM, McEwen BS, Gorman JM, LeDoux JE (2004). The selective serotonin reuptake inhibitor citalopram increases fear after acute treatment but reduces fear with chronic treatment: a comparison with tianeptine. Biol Psychiatry 55: 1171-1178.

Carpenter LL, Anderson GM, Pelton GH, Gudin JA, Kirwin PD, Price LH et al (1998). Tryptophan depletion during continuous CSF sampling in healthy human subjects. Neuropsychopharmacology 19: 26-35.

Cassella JV, Davis M (1985). Fear-enhanced acoustic startle is not attenuated by acute or chronic imipramine treatment in rats. Psychopharmacology 87: 278-282.

Chamberlain SR, Muller U, Blackwell AD, Clark L, Robbins TW, Sahakian BJ (2006). Neurochemical modulation of response inhibition and probabilistic learning in humans. Science 311: 861-863.

Cools R, Roberts AC, Robbins TW (2008a). Serotoninergic regulation of emotional and behavioural control processes. Trends Cogn Sci 12: 31-40.

Cools R, Robinson OJ, Sahakian B (2008b). Acute tryptophan depletion in healthy volunteers enhances punishment prediction but does not affect reward prediction. Neuropsychopharmacology 33: 2291-2299.

Cooney R, Joormann J, Eugène F, Dennis E, Gotlib I (2010). Neural correlates of rumination in depression. Cogn Affect Behav Neurosci 10: 470-478.

Crockett MJ, Clark L, Robbins TW (2009). Reconciling the role of serotonin in behavioral inhibition and aversion: acute tryptophan depletion abolishes punishment-induced inhibition in humans. J Neurosci 29: 11993-11999.

Crockett MJ, Clark L, Roiser JP, Robinson OJ, Cools R, Chase HW et al (2012). Converging evidence for central 5-HT effects in acute tryptophan depletion. Mol Psychiatry 17: 121-123.

Davis M, Cassella JV, Kehne JH (1988). Serotonin does not mediate anxiolytic effects of buspirone in the fear-potentiated startle paradigm: comparison with 8-OH-DPAT and ipsapirone. Psychopharmacology 94: 14-20.

Davis M, Walker DL, Miles L, Grillon C (2010). Phasic vs sustained fear in rats and humans: role of the extended amygdala in fear vs anxiety. Neuropsychopharmacology 35: 105-135.

Dayan P, Huys QJM (2008). Serotonin, inhibition, and negative mood. PLoS Comput Biol 4: e4.

Dayan P, Huys QJ (2009). Serotonin in affective control. Annu Rev Neurosci 32: 95-126.

de Bellis MD, Gold PW, Geracioti TD, Listwak SJ (1993). Association of fluoxetine treatment with reductions in CSF concentrations of corticotropin-releasing hormone and arginine vasopressin in patients with major depression. Am J Psychiatry 150: $656-657$. 
de Jongh R, Groenink L, van der Gugten J, Olivier B (2003). Lightenhanced and fear-potentiated startle: temporal characteristics and effects of $\alpha$-helical corticotropin-releasing hormone. Biol Psychiatry 54: 1041-1048.

First MB, Spitzer RL, Gibbon M, Williams JBW (2002). Structured Clinical Interview for DSM-IV-TR Axis I Disorders-Patient edition (SCID-I/P, 11/2002 Revision). New York State Psychiatric Institute: New York.

Grillon C (2008a). Greater sustained anxiety but not phasic fear in women compared to men. Emotion 8: 410-413.

Grillon C (2008b). Models and mechanisms of anxiety: evidence from startle studies. Psychopharmacology 199: 421-437.

Grillon C, Baas JMP, Cornwell B, Johnson L (2006a). Context conditioning and behavioral avoidance in a virtual reality environment: effect of predictability. Biol Psychiatry 60: 752-759.

Grillon C, Baas JMP, Pine DS, Lissek S, Lawley M, Ellis V et al (2006b). The benzodiazepine alprazolam dissociates contextual fear from cued fear in humans as assessed by fear-potentiated startle. Biol Psychiatry 60: 760-766.

Grillon C, Baas JP, Lissek S, Smith K, Milstein J (2004). Anxious responses to predictable and unpredictable aversive events. Behav Neurosci 118: 916-924.

Grillon C, Chavis C, Covington MF, Pine DS (2008a). Two-week treatment with the selective serotonin reuptake inhibitor citalopram reduces contextual anxiety but not cued fear in healthy volunteers: a fear-potentiated startle study. Neuropsychopharmacology 34: 964-971.

Grillon C, Heller R, Hirschhorn E, Kling MA, Pine DS, Schulkin J et al (2011a). Acute hydrocortisone treatment increases anxiety but not fear in healthy volunteers: a fear-potentiated startle study. Biol Psychiatry 69: 549-555.

Grillon C, Heller R, Hirschhorn E, Kling MA, Pine DS, Schulkin J et al (2011b). Acute hydrocortisone treatment increases anxiety but not fear in healthy volunteers: a fear-potentiated startle study. Biol Psychiatry 69: 549-555.

Grillon C, Levenson J, Pine DS (2006c). A single dose of the selective serotonin reuptake inhibitor citalopram exacerbates anxiety in humans: a fear-potentiated startle study. Neuropsychopharmacology 32: 225-231.

Grillon C, Lissek S, Rabin S, McDowell D, Dvir S, Pine DS (2008b). Increased anxiety during anticipation of unpredictable but not predictable aversive stimuli as a psychophysiologic marker of panic disorder. Am J Psychiatry 165: 898-904.

Grillon C, Pine DS, Lissek S, Rabin S, Bonne O, Vythilingam M (2009). Increased anxiety during anticipation of unpredictable aversive stimuli in posttraumatic stress disorder but not in generalized anxiety disorder. Biol Psychiatry 66: 47-53.

Hammack SE, Guo J-D, Hazra R, Dabrowska J, Myers KM, Rainnie DG (2009). The response of neurons in the bed nucleus of the stria terminalis to serotonin: implications for anxiety. Prog Neuropsychopharmacol Biol Psychiatry 33: 1309-1320.

Harmer CJ (2008). Serotonin and emotional processing: does it help explain antidepressant drug action? Neuropharmacology 55: 1023-1028.

Inoue T, Kitaichi Y, Koyama T (2011). SSRIs and conditioned fear. Prog Neuropsychopharmacol Biol Psychiatry 35: 1810-1819.

Insel T, Cuthbert B, Garvey M, Heinssen R, Pine DS, Quinn K et al (2010). Research domain criteria (RDoC): toward a new classification framework for research on mental disorders. Am J Psychiatry 167: 748-751.

Joordens R, Hijzen T, Olivier B, Peeters B (1996). Fear-potentiated startle response is remarkably similar in two laboratories. Psychopharmacology 126: 104-109.

Klemenhagen KC, Gordon JA, David DJ, Hen R, Gross CT (2005). Increased fear response to contextual cues in mice lacking the 5-HT1A receptor. Neuropsychopharmacology 31: 101-111.
Levita L, Hammack SE, Mania I, Li XY, Davis M, Rainnie DG (2004). 5-hydroxytryptaminela-likereceptor activation in the bed nucleus of the stria terminalis: electrophysiological and behavioral studies. Neuroscience 128: 583-596.

McNaughton N, Corr PJ (2004). A two-dimensional neuropsychology of defense: fear/anxiety and defensive distance. Neurosci Biobehav Rev 28: 285-305.

Milad MR, Wright CI, Orr SP, Pitman RK, Quirk GJ, Rauch SL (2007). Recall of fear extinction in humans activates the ventromedial prefrontal cortex and hippocampus in concert. Biol Psychiatry 62: 446-454.

Miles L, Davis M, Walker D (2011). Phasic and sustained fear are pharmacologically dissociable in rats. Neuropsychopharmacology 36: $1563-1574$.

Mineka S, Hendersen RW (1985). Controllability and predictability in acquired motivation. Annu Rev Psychol 36: 495-529.

Murrough JW, Huang Y, Hu J, Henry S, Williams W, Gallezot J-D et al (2011). Reduced amygdala serotonin transporter binding in posttraumatic stress disorder. Biol Psychiatry 70: 1033-1038.

Nolen-Hoeksema $S$ (2000). The role of rumination in depressive disorders and mixed anxiety/depressive symptoms. J Abnorm Psychol 109: 504-511.

Otto T, Poon P (2006). Dorsal hippocampal contributions to unimodal contextual conditioning. J Neurosci 26: 6603-6609.

Passamonti L, Crockett MJ, Apergis-Schoute AM, Clark L, Rowe JB, Calder AJ et al (2012). Effects of acute tryptophan depletion on prefrontal-amygdala connectivity while viewing facial signals of aggression. Biol Psychiatry 71: 36-43.

Phelix CF, Liposits Z, Paull WK (1992). Serotonin-CRF interaction in the bed nucleus of the stria terminalis: a light microscopic double-label immunocytochemical analysis. Brain Res Bull 28: 943-948.

Robinson OJ (2011). Brain burdens: boost resilience to tackle mental illness. Nature 478: 459.

Robinson OJ, Cools R, Sahakian BJ (2011). Tryptophan depletion disinhibits punishment but not reward prediction: implications for resilience. Psychopharmacology 219: 599-605.

Robinson OJ, Sahakian BJ (2009). Acute tryptophan depletion evokes negative mood in healthy females who have previously experienced concurrent negative mood and tryptophan depletion. Psychopharmacology (Berl) 205: 227-235.

Sanislow CA, Pine DS, Quinn KJ, Kozak MJ, Garvey MA, Heinssen RK et al (2010). Developing constructs for psychopathology research: research domain criteria. J Abnorm Psychol 119: 631-639.

Schmitz A, Grillon C (2012). The NPU-threat test: assessing fear and anxiety in humans using threat of predictable and unpredictable aversive events. Nat Protoc 7: 527-532.

Schulkin J, Morgan MA, Rosen JB (2005). A neuroendocrine mechanism for sustaining fear. Trends Neurosci 28: 629-635.

Silva RCB, Gárgaro AC, Brandão ML (2004). Differential regulation of the expression of contextual freezing and fear-potentiated startle by 5 -HT mechanisms of the median raphe nucleus. Behav Brain Res 151: 93-101.

Soubrié P (1986). Reconciling the role of central serotonin neurons in human and animal behaviour. Behav Brain Sci 9: 319-364.

Spielberger CD (1996). State Trait Anxiety Inventory. John Wiley \& Sons: New York, NY.

Toufexis DJ, Davis C, Hammond A, Davis M (2004). Progesterone attenuates corticotropin-releasing factor-enhanced but not fearpotentiated startle via the activity of its neuroactive metabolite, allopregnanolone. J Neurosci 24: 10280-10287.

Tyrka AR, Carpenter LL, McDougle CJ, Kirwin PD, Owens MJ, Nemeroff CB et al (2004). Increased cerebrospinal fluid corticotropin-releasing factor concentrations during tryptophan depletion in healthy adults. Biol Psychiatry 56: 531-534. 
van Donkelaar EL, Blokland A, Ferrington L, Kelly PAT, Steinbusch HWM, Prickaerts J (2011). Mechanism of acute tryptophan depletion: is it only serotonin? Mol Psychiatry 16: 695-713.

Vansteenwegen D, Iberico C, Vervliet B, Marescau V, Hermans D (2008). Contextual fear induced by unpredictability in a human fear conditioning preparation is related to the chronic expectation of a threatening US. Biol Psychology 77: 39-46.
Young SN, Smith SE, Pihl RO, Ervin FR (1985). Tryptophan depletion causes a rapid lowering of mood in normal males. Psychopharmacology 87: 173-177.

Zangrossi Jr H, Viana MB, Zanoveli JN, Bueno CN, Nogueira RL, Graeff FG (2001). Serotonergic regulation of inhibitory avoidance and one-way escape in the rat elevated T-maze. Neurosci Biobehav Rev 25: 637-645.

Supplementary Information accompanies the paper on the Neuropsychopharmacology website (http://www.nature.com/npp) 